\title{
Seed Extract-mediated Synthesis of Silver Nanoparticles from Putranjiva roxburghii Wall., Phytochemical Characterization, Antibacterial Activity and Anticancer Activity Against MCF-7 Cell Line
}

\author{
S. NAYAKA*, M. P. BHAT, B. CHAKRABORTY, S. S. PALLAVI, D. AIRODAGI, R. MUTHURAJ, H. M. HALASWAMY, \\ S. B. DHANYAKUMARA, K. N. SHASHIRAJ AND CHANDANA KUPANESHI \\ Department of Studies in Botany, Karnatak University, Dharwad-580 003, India
}

Nayaka et al.: Synthesis and evaluation of Silver Nanoparticles from Putranjiva roxburghii Wall

\begin{abstract}
The present study was focused on the green synthesis of silver nanoparticles using the aqueous extract of Putranjiva roxburghii seed and investigation of antibacterial activity of the nanoparticles. Further, the synthesized silver nanoparticles were tested on human breast cancer cell line the potential tumour suppressing property for antitumour activity. The seed extract was investigated for the presence of secondary metabolites and the formation of silver nanoparticles was indicated by a colour change from pale yellow to brown. The synthesis of the silver nanoparticles was ascertained with UV/Vis spectroscopy, atomic force microscopy, X-ray powder diffraction, energy dispersive X-ray analysis, Fourier Transform infrared spectroscopy and transmission electron microscopy. Antibacterial and anticancer activity of the synthesized silver nanoparticles was tested using agar well diffusion and 96 well plate mean transit time cell proliferation assay methods, respectively. The results showed that silver nanoparticles were spherical, 13$69 \mathrm{~nm}$ in size with a maximum absorption peak at $371 \mathrm{~nm}$. These silver nanoparticles showed considerable antibacterial effects on Staphylococcus aureus, Streptococcus pneumoniae and Enterococcus faecalis except on Escherichia coli. The cytotoxic effect of the silver nanoparticles was tested on human breast cancer cell line. The decrease in \% viability of the human breast cancer cell line cells was observed at 12.5 to $200 \mu \mathrm{g} / \mu \mathrm{l}$ concentration with an $\mathrm{IC}_{50}$ of $72.32 \mu \mathrm{g} / \mathrm{ml}$. It is an easy, inexpensive and eco-friendly approach for the biosynthesis of silver nanoparticles from Putranjiva roxburghii seed extract and the nanoparticles exhibited antibacterial activity and a potential to be used against human breast cancer.
\end{abstract}

Key words: Silver nanoparticles, Putranjiva roxburghii, green synthesis, phytochemical test, antibacterial, anticancer activityy

Nanotechnology is emerging as an area of intense scientific research, due to a wide variety of potential applications in the modern material world ${ }^{[1]}$. Nanoparticles (NPs) possess a very small size and very high surface to volume ratio ${ }^{[2]}$. Green nanotechnology is emerging into an important tool for the synthesis of nanoparticles. Biological synthesis of NPs is very well known as green chemistry, and it is growing in to a simple but effective alternative to chemical procedures to obtain NPs and also it is non-toxic, easy and environmental friendly ${ }^{[3-6]}$. The synthesis of metal NPs can be done by employing many methods such as physical, chemical, photochemical and biological synthesis. The use of microbes and plants for the

*Address for correspondence E-mail:sreenivasankud@gmail.com

March-April 2020 reduction of metal ions is found to be much faster and stable at different physical conditions ${ }^{[7]}$. Among the metal NPs, gold and silver NPs have been used more often for various applications ${ }^{[8]}$. Silver nanoparticles (AgNPs) have some unique properties like surfaceenhanced Raman scattering, high electrical and thermal conductivity, surface plasmon resonance and chemical stability ${ }^{[9]}$. Plants contain different kinds of metabolites

This is an open access article distributed under the terms of the Creative Commons Attribution-NonCommercial-ShareAlike 3.0 License, which allows others to remix, tweak, and build upon the work non-commercially, as long as the author is credited and the new creations are licensed under the identical terms

Accepted 23 January 2020

Revised 23 December 2019

Received 04 November 2019 Indian J Pharm Sci 2020;82(2):260-269 
such as alkaloids, terpenoids, polyphenols, phenolic acids, sugars and proteins to play an important role in the bio-reduction of ionic silver $\left(\mathrm{Ag}^{+}\right)$to elemental silver $\left(\mathrm{Ag}^{0}\right)$, and these act as capping and stabilising agents ${ }^{[10]}$. AgNPs can be obtained through green synthesis using plant extracts and microbial cell biomass or cells ${ }^{[11]}$. Due to the ease of large-scale synthesis and maintenance-free, plants or plant extracts are more preferred for NP synthesis than microbes ${ }^{[12,13]}$. The pre-established plant secondary metabolites play an important role in the reduction and stabilization of $\mathrm{Ag}^{+[10]}$. For the synthesis of AgNPs, various parts of plants or their extracts have been extensively used and phytosynthesis is considered as an easier and more rapid method among the biological processes ${ }^{[14]}$.

Putranjiva roxburghii (P. roxburghii) has been described as an important plant in the traditional Ayurvedic and Unani systems. Various parts of $P$. roxburghii are used for the treatment of different diseases ${ }^{[15,16]}$. The leaves are used to treat inflammatory and eye diseases, while the seeds are used orally in the form of a powder for the treatment of burning sensation, thirst, dysuria, elephantiasis, ophthalmic diseases, constipation, semen disorders, infertility, diseases of female genital organs and also as an aphrodisiac ${ }^{17,18]}$. There are reports of green synthesis of AgNPs using various parts of $P$. roxburghii and their antimicrobial activity ${ }^{[19]}$ but the synthesis of AgNPs from seed extract and their biological activity was not reported even though there were reports about the medicinal uses of $P$. roxburghii seeds ${ }^{[16,17]}$. The present study is focused on the green synthesis of AgNPs using the aqueous extract of $P$. roxburghii seeds and investigation of the antibacterial and anticancer activity possessed by these AgNPs.

\section{MATERIALS AND METHODS}

P. roxburghii seeds were collected from a commercial Ayurvedic store near Dharwad, Karnataka and authenticated by comparing with the sample existing in the herbarium at the depository of plants and animals museum, Karnatak University, Dharwad and literature of traditional medicinal plants. $\mathrm{AgNO}_{3}$ and nutrient agar were procured from Himedia Laboratory. Staphylococcus aureus (MTCC 6908), Escherichia coli (MTCC 40), Streptococcus pneumoniae (MTCC 9238) and Enterococcus faecalis (MTCC 6845) were procured from NCL Pune.

\section{Preparation of seed extract:}

P. roxburghii seeds were used to synthesise AgNPs. The seeds were washed several times with distilled water to remove dust particles and other debris. Then the dried seeds were crushed into a fine powder using a mortar and pestle. Ten grams of the seed powder was suspended in $100 \mathrm{ml}$ of distilled water, heated for $1 \mathrm{~h}$ at $80^{\circ}$. The mixture was allowed to cool, filtered through Whatman No.1 filter paper and then centrifuged at $5000 \mathrm{rpm}$ for 5 min. The filtrate was collected in a conical flask and was stored in a refrigerator at $4^{\circ}$ for further use ${ }^{[19]}$. Standard methods was used for the phytochemical analysis of $P$. roxburghii seed aqueous extract ${ }^{[20,21]}$.

\section{Preparation of AgNPs from the seed extract:}

For the synthesis of $\mathrm{AgNPs}, 0.1 \mathrm{mM} \mathrm{AgNO}$, solution was prepared, $86 \%$ of $\mathrm{AgNO}_{3}$ solution was mixed with $14 \%$ seed extract and the $\mathrm{pH}$ was adjusted to 8.5 . The colour change from yellow to reddish-brown was observed, which indicated reduction of $\mathrm{Ag}^{+}$to $\mathrm{Ag}^{0} \mathrm{NPs}$. Finally, the synthesized nanoparticles were air-dried and collected in Eppendorf tubes to carry out further analysis ${ }^{[19]}$.

\section{UV/Vis spectroscopy:}

The spectrophotometric analysis of the synthesized AgNPs was carried out to measure the absorption maximum of AgNPs on a UV/Vis double-beam spectrophotometer (Metash UV-9000A). The synthesized AgNPs were scanned at different wavelengths periodically from 200 to $700 \mathrm{~nm}$ at room temperature. The absorption spectrum of the AgNPs was plotted with wavelength on $\mathrm{X}$-axis and absorbance on Y-axis ${ }^{[14]}$.

\section{Atomic force microscopy (AFM):}

The purified AgNP suspension was freeze-dried to obtain a powder and a thin film of sample was prepared to perform AFM which reveals the morphological details. The AgNPs were scanned with AFM (Nano Surf Flex AFM) to determine the distribution and surface morphology of the synthesized $\operatorname{AgNPs}^{[22]}$.

\section{X-ray diffraction (XRD):}

XRD measurement of the AgNPs was carried out using a solution drop coated on a glass substrate on an X-ray diffractometer, operated at a voltage of $3 \mathrm{keV}$. The phase formation was analysed by XRD analyser (Rigaku Miniflex 600) in the $2 \theta$ range from 30 to $80^{\circ}$ at the scanning rate of $4 \% \mathrm{~min}$. The intensities measured with XRD can provide quantitative, accurate information on the atomic arrangements at interfaces ${ }^{[14]}$. 


\section{Energy-dispersive X-ray (EDX) spectroscopy:}

EDX was employed to determine the presence of various elements and to measure their relative proportions. Initial EDX analysis usually involved the generation of an X-ray spectrum from the entire scan area to detect the different elements in a sample ${ }^{[14]}$.

\section{Transmission electron microscopy (TEM):}

TEM is helpful for the direct imaging of the atomic structure of the sample, the exact structure and diameter of the sample particle can be determined by the highresolution images. The dried AgNPs were characterized by TEM (Hitachi, Model: S-3400N) ${ }^{[11]}$.

\section{Fourier transform infrared (FTIR) spectroscopy}

The functional group analysis was characterized by FTIR (Nicolet 6700) and a spectrum was recorded in the region of 4000 to $400 \mathrm{~cm}^{-1}$. The sample gave peaks at different wavenumbers, according to the peak values the possible functional groups are interpreted to know the structure of the synthesized NPs ${ }^{[19]}$.

\section{Antibacterial activity of AgNPs:}

The antibacterial activity of AgNPs was determined against Gram-positive bacteria such as Streptococcus pneumoniae, Staphylococcus aureus, Enterococcus faecalis and a Gram-negative bacterium Escherichia coli using the agar well diffusion method ${ }^{[10]}$ on MuellerHinton agar medium ( $\mathrm{pH}$ 7.4). The test organisms were spread on separate Mueller-Hinton agar medium plates and wells of $6 \mathrm{~mm}$ diameter were made on $4 \mathrm{~mm}$ thick media. $\mathrm{AgNO}_{3}$ solution was filled in a well as a control, AgNPs suspension at concentrations of 25, 50, 75 and $100 \mu \mathrm{g} / \mathrm{ml}$ were filled in separate wells. These plates were incubated overnight at $37^{\circ}$ for $24 \mathrm{~h}^{[4]}$. After the incubation period, the antibacterial activities were determined by measuring inhibition zone diameter.

\section{Anticancer activity of AgNPs:}

Cell viability was measured using MTT assay, which would give effect of AgNPs on cell proliferation and cytotoxicity. Briefly, the MTT assay is based on the reduction of yellow coloured water-soluble tetrazolium dye to formazan crystals. The human breast cancer (MCF-7) cell line was procured from NCCS, Pune. The cells were sub cultured and maintained until they reach $70 \%$ confluence in T25 flasks at $37^{\circ}$ in a $5 \% \mathrm{CO}_{2}$ incubator. Medium control (medium without cells), negative control (medium with cells but without test compound) and positive control (medium with cells and
$15 \mu \mathrm{M}$ of camptothecin) were used. During the assay, the MCF-7 cells were plated onto 96 well (Thermoscientific Nunc, Cat. No. 167008) flat-bottom plates at a cell density of 20000 cells/well and the cells were allowed to grow for $24 \mathrm{~h}$. These cells were then treated with $12.5,25,50,100$ and $200 \mu \mathrm{g} / \mathrm{ml}$ concentrations of AgNPs suspension for $24 \mathrm{~h}$ followed by the addition of MTT reagent to get a final concentration of $0.5 \mathrm{mg} /$ $\mathrm{ml}$. The plates were incubated for $24 \mathrm{~h}$ at $37^{\circ}$ in a $5 \%$ $\mathrm{CO}_{2}$ atmosphere. After incubation, the spent media was removed and the plates were wrapped with aluminium foil to avoid exposure to light and again incubated for 3 $h$. Then the product of MTT reduction (formazan) was dissolved in $100 \mu \mathrm{l}$ of DMSO with gentle shaking and the absorbance was read on an ELISA reader at $570 \mathrm{~nm}$ and $630 \mathrm{~nm}$ was used as reference wavelength ${ }^{[23]}$.

\section{RESULTS AND DISCUSSION}

Preliminary screening for secondary metabolites of the $P$. roxburghii seed extract indicated the presence of alkaloids, flavonoids, amino acids, proteins, saponins, fats and oils, while cardiac glycosides, phenols, phlobatannins, tannins, and quinones were absent (Table 1). These phytochemicals in the seed extract could be extracted by polar solvents water, methanol and ethanol, while the remaining phytochemicals listed above could not be extracted due to their nonpolar nature. Previously similar phytochemical analysis results were reported from aqueous and methanol extracts of various parts of $P$. roxburghii plant ${ }^{[20,21]}$. The AgNPs were successfully synthesized using the aqueous extract of $P$. roxburghii seeds as the reducing source. Fig. 1a and b show the $P$. roxburghii seeds and the finely ground seed powder, respectively. The $\mathrm{AgNO}_{3}$ solution $(0.1 \mathrm{mM})$ was colourless and the colour of the seed extract before and after the addition of $\mathrm{AgNO}_{3}$ was changed from pale yellow to brown as shown in fig. 1c and $d$. This colour change was due to the interaction of

TABLE 1: PHYTOCHEMICAL ANALYSIS OF P. ROXBURGHII SEED AQUEOUS EXTRACT

\begin{tabular}{|c|c|}
\hline Test for & Results \\
\hline alkaloids & + \\
\hline cardiac glycosides & 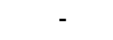 \\
\hline flavonoids & + \\
\hline phenols & - \\
\hline phlobotannins & - \\
\hline amino acid and proteins & + \\
\hline saponins & + \\
\hline tannins & - \\
\hline terpenoids & - \\
\hline quinones & - \\
\hline fats and oils & + \\
\hline
\end{tabular}


$\mathrm{AgNO}_{3}$ with plant extract leading to the reduction of silver nitrate to elemental silver $\left(\mathrm{Ag}^{+} \text {to } \mathrm{Ag}^{0}\right)^{[24]}$. The $\mathrm{UV} / \mathrm{Vis}$ spectrum of AgNPs synthesized in the range of 200 to $700 \mathrm{~nm}$ is shown in fig. 2 and the AgNPs gave the maximum absorption peak at $371 \mathrm{~nm}$. The appearance of the peak was the characteristic of surface plasmon resonance (SPR) of AgNPs and the free electrons gave rise to the SPR absorption band, which occurred due to the collective oscillation of AgNP in resonance with the light wave ${ }^{[25]}$. Some other reports also stated that the UV/Vis absorption peaks for biogenic AgNPs were obtained at $378 \mathrm{~nm}$ and $384 \mathrm{~nm}^{[24,26]}$.

The AFM data revealed that the AgNPs were monodispersed and spherical in shape. The size of the nanoparticles ranged from 13.64 to $69.04 \mathrm{~nm}$ in 2 and 3 -dimensional structures with a height of $18.9 \mathrm{~nm}$. The distance from each other was $38.43 \mathrm{~nm}$ and was shown in fig. 3a-c. Almost similar result about the morphology and size of AgNPs around 30-50 nm was reported ${ }^{[22]}$.

The synthesised AgNPs from $P$. roxburghii were characterized using powder XRD to confirm the particles as $\mathrm{Ag}$ and to know the structural information. Fig. 4 revealed the XRD pattern of the synthesized AgNPs and the characteristic diffraction peaks were found at $38.12^{\circ}, 46.39^{\circ}, 64.60^{\circ}$ and $76.79^{\circ}$ with the XRD planes at 111, 200, 220 and 311, respectively. These values corresponded with the previously reported values for AgNPs prepared from plant extracts and also the AgNPs appeared to be face centred cubic (FCC) crystals in nature ${ }^{[5,12]}$.

The sample was analysed with EDX at $3 \mathrm{keV}$ to measure the elemental constituents involved in the formation of these AgNPs from P. roxburghii seed extract because generally metallic AgNPs show typical optical absorption peak approximately at $3 \mathrm{keV}$ due to $\mathrm{SPR}^{[14,27]}$. The EDX was employed for the qualitative and quantitative analysis of the possible elements in the synthesized NPs and that showed $31.21 \pm 0.82 \%$ of carbon, $37.84 \pm 1.93 \%$ of oxygen, $4.82 \pm 0.33 \%$ of phosphorous, $2.28 \pm 0.30 \%$ of sulphur, $2.77 \pm 0.76 \%$ of molybdenum and $21.08 \pm 1.00 \%$ of silver and among these elements carbon was from plant and the other
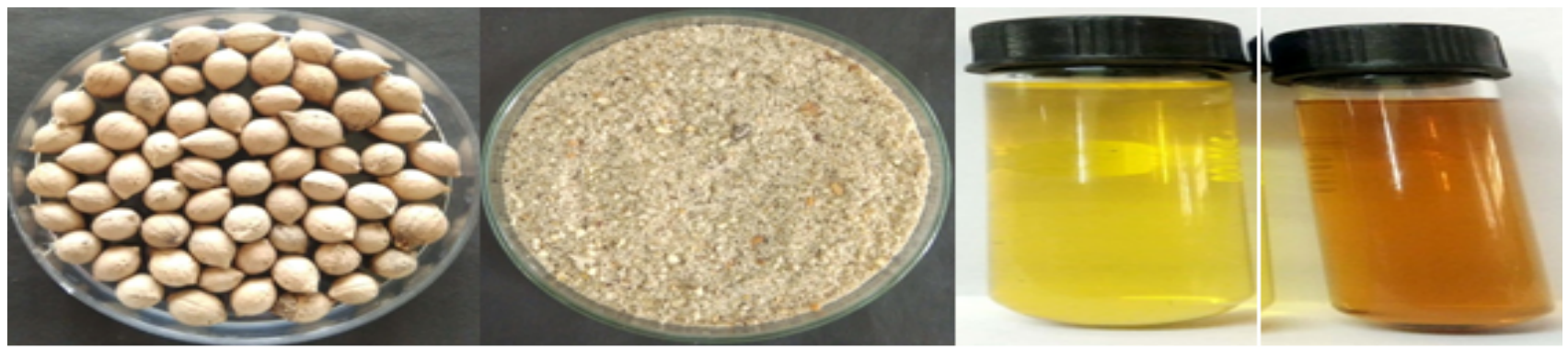

Fig. 1: Synthesis of AgNPs from $P$. roxburghii seed extract

a) $P$. roxburghii seeds with seed coat b) seed powder c) aqueous seed extract d) colour change after adding $0.1 \mathrm{mM}$ $\mathrm{AgNO}_{3}$ solution

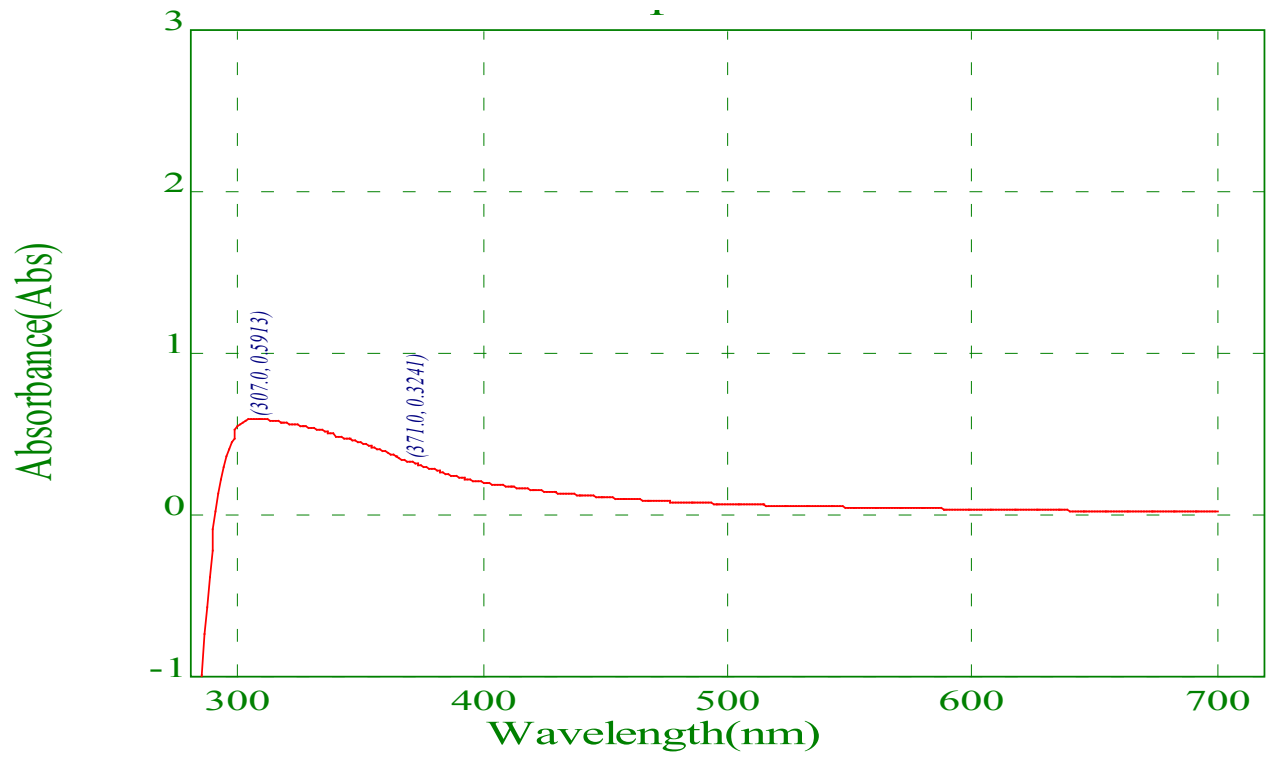

Fig. 2: UV/Vis absorbance spectra of synthesized AgNPs from P. roxburghii seed extract 


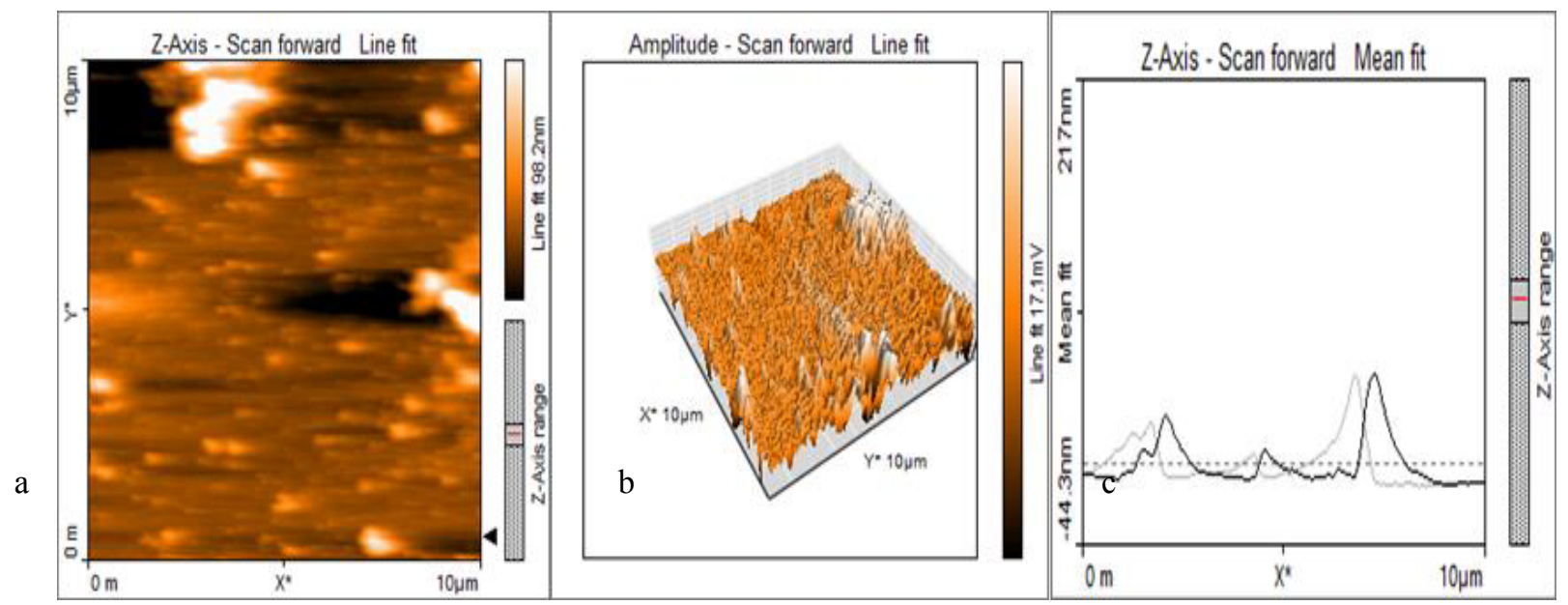

Fig. 3: AFM image of synthesized AgNPs from $P$. roxburghii seed extract

a) Two dimensional structure b) three dimensional structure and c) particle size distribution

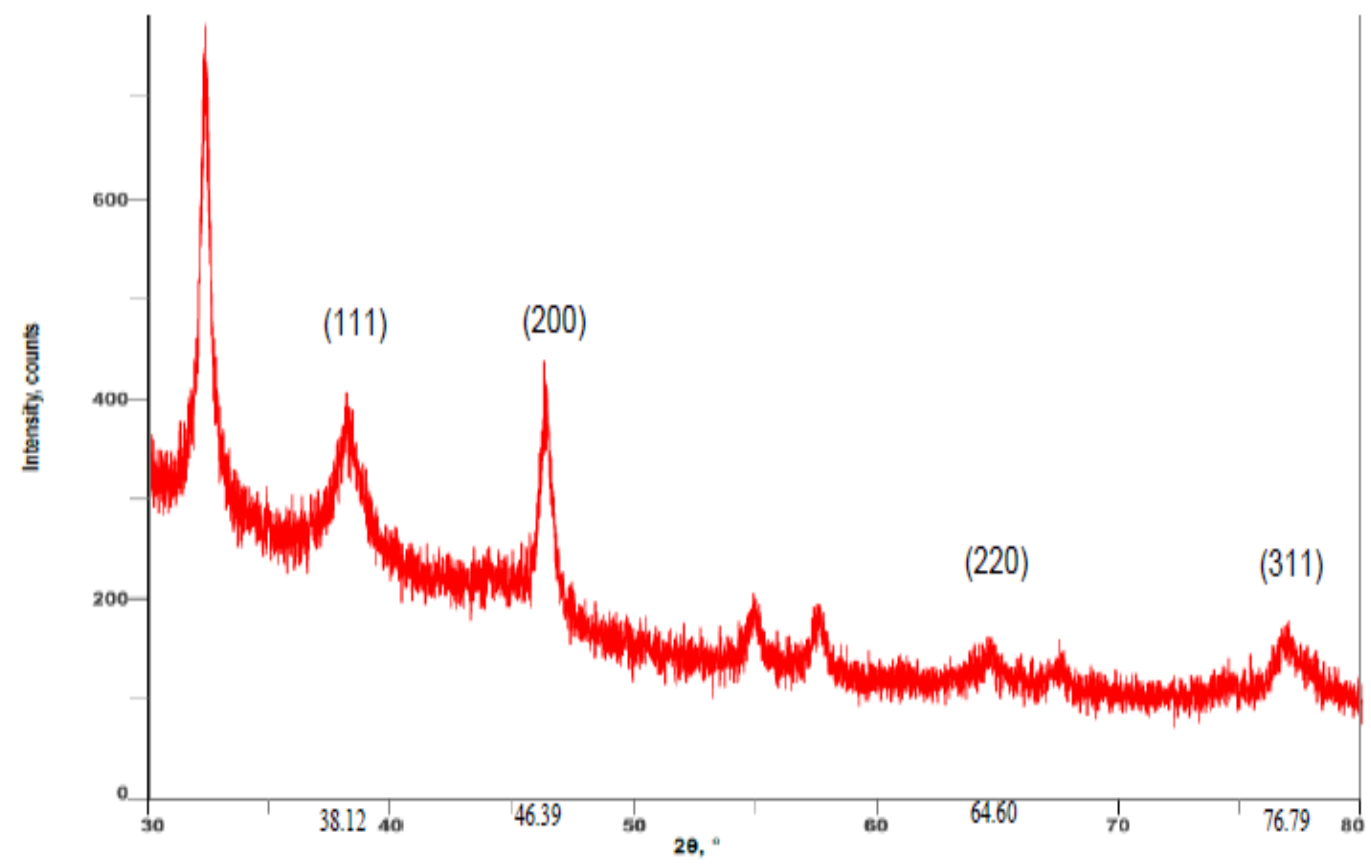

Fig. 4: XRD pattern of synthesized AgNPs from $P$. roxburghii seed extract

elements were from the plant metabolites involved in the capping of the synthesized $\mathrm{AgNPs}^{[28]}$. All these values were presented in fig. 5 .

The synthesized AgNPs were analysed with TEM to confirm the morphology and size and the TEM image shown in fig. 6 depicted that the AgNPs were spherical in shape with a high surface area. The size of these AgNPs was in the range of 13.94 to $52.46 \mathrm{~nm}$ with average size of $25.68 \mathrm{~nm}$. The TEM analysis of AgNPs synthesized from various plants and plant extracts showed more variation in size from 5 to $100 \mathrm{~nm}$ and the shape was somewhat oblong to spherical ${ }^{[11,12,19]}$.

The FTIR analysis of $P$. roxburghii seed aqueous extract and that of AgNPs prepared from aqueous seed extract revealed IR bands at wavenumbers 464 to $3401 \mathrm{~cm}^{-1}$ and 470 to $3393 \mathrm{~cm}^{-1}$, respectively as shown in figs. $7 \mathrm{a}$ and $\mathrm{b}$. The FTIR spectrum of seed powder revealed a medium band at $3401 \mathrm{~cm}^{-1}$, which attributed to stretching aliphatic primary amines $(\mathrm{N}-\mathrm{H})$, the strong and sharp band at $2923 \mathrm{~cm}^{-1}$ corresponded to $\mathrm{C}-\mathrm{H}$ stretching alkane and the medium band at 2852 $\mathrm{cm}^{-1}$ represented $\mathrm{C}-\mathrm{H}$ stretching aldehydes. The two strong sharp bands at 2359 and $2341 \mathrm{~cm}^{-1}$ were due to $\mathrm{O}=\mathrm{C}=\mathrm{O}$ stretching $\mathrm{CO}_{2}$, the bands at $1633,1538,1455$, and 1384 belonged to $\mathrm{C}=\mathrm{C}$ stretching alkenes, $\mathrm{N}-\mathrm{O}$ stretching nitro compound and $\mathrm{C}-\mathrm{H}$ bending alkane, respectively. The weak bands at 1257, 1032, and 668 represented $\mathrm{C}-\mathrm{N}$ stretching amines, $\mathrm{S}=\mathrm{O}$ stretching sulfoxide and $\mathrm{C}=\mathrm{C}$ bending alkene, respectively. For 


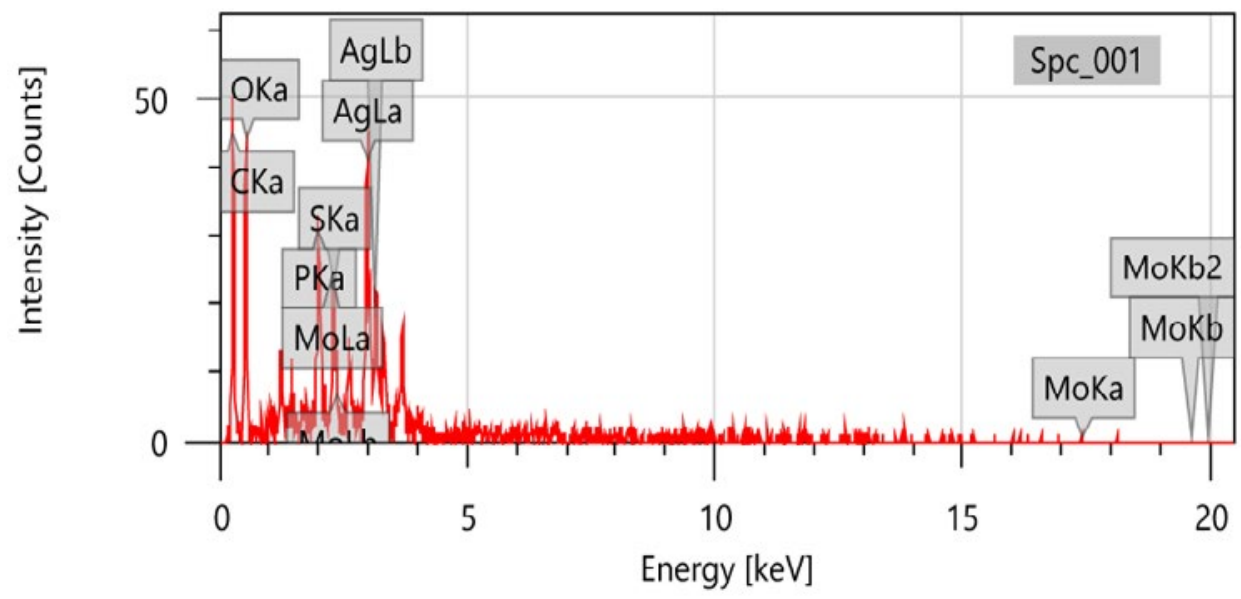

Fig. 5: EDX image of synthesized AgNPs from P. roxburghii seed extract

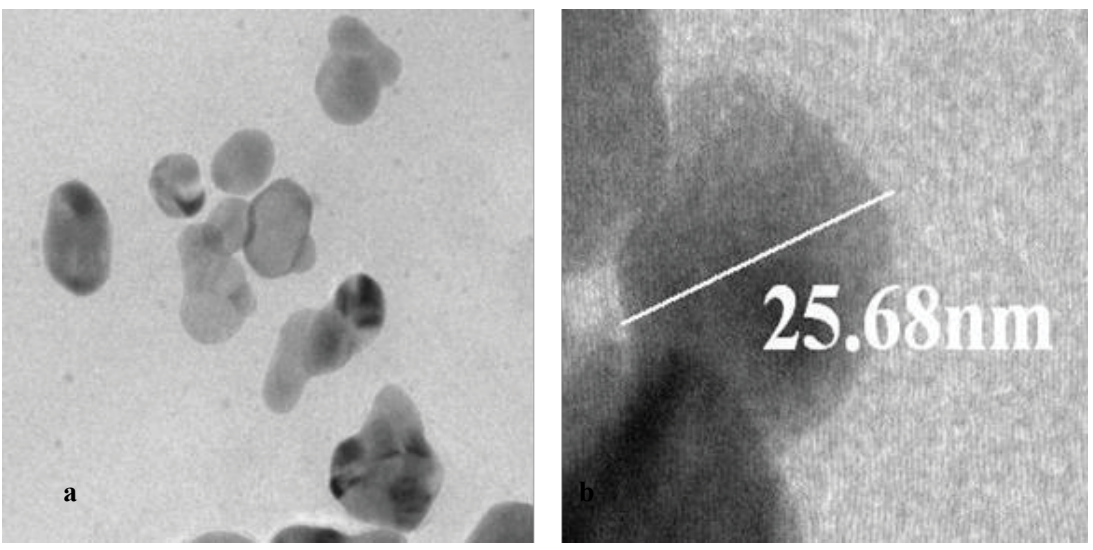

Fig. 6: TEM images of synthesized AgNPs from $P$. roxburghii seed extract a) Image showing the shape of AgNPs and b) image showing average size

a.

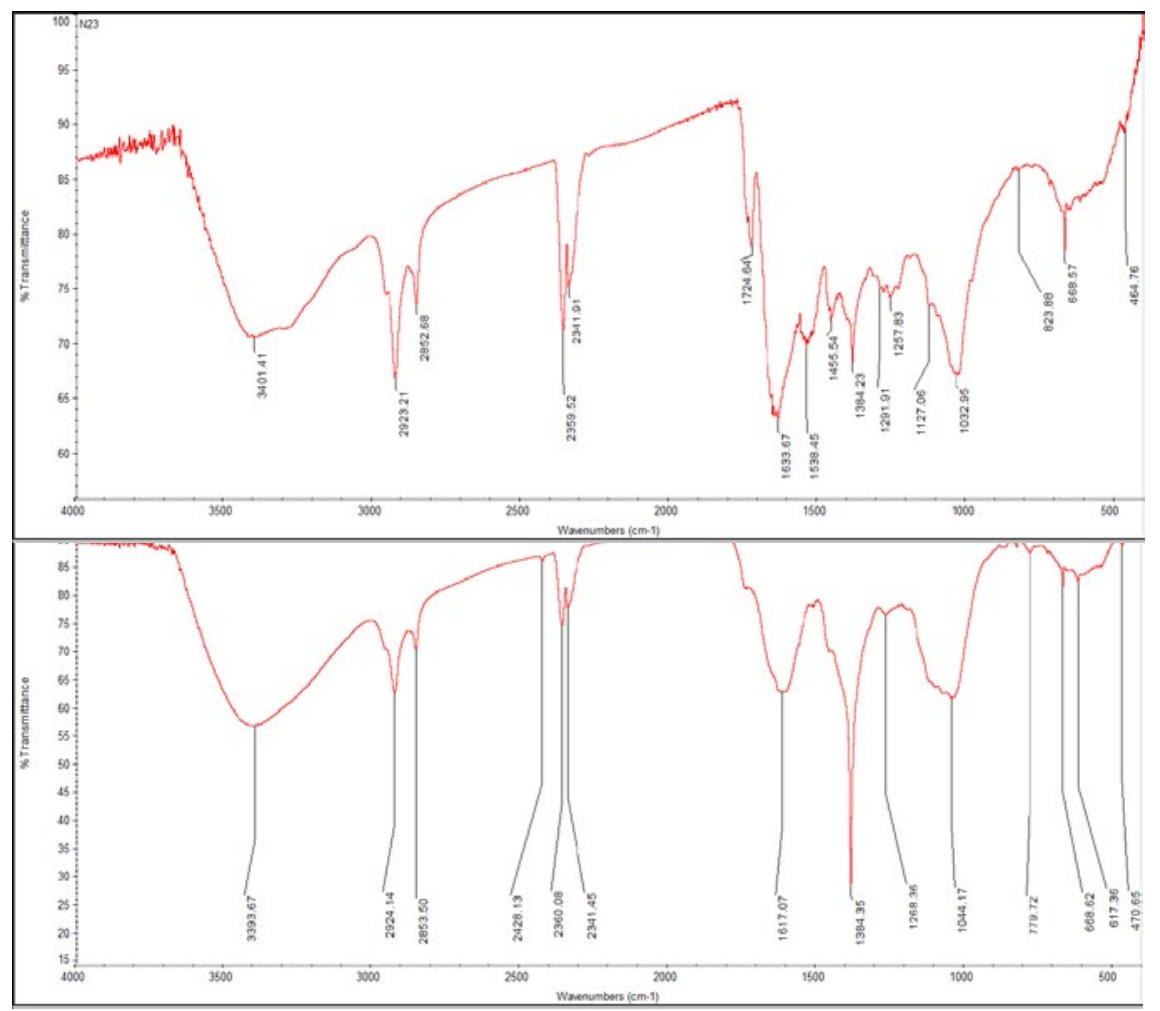

Fig. 7: FTIR spectra of $P$. roxburghii seed and the synthesized AgNPs FTIR spectra of a) P. roxburghii seed powder and b) synthesized AgNPs 


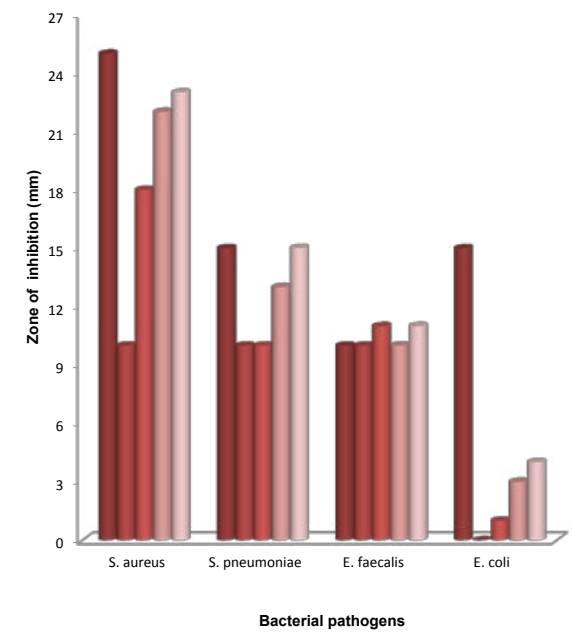

Fig. 8: Antibacterial activity of AgNPs at different concentrations

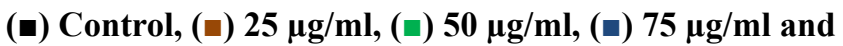
(口) $100 \mu \mathrm{g} / \mathrm{ml}$ the synthesized AgNPs, the FTIR band at $3393 \mathrm{~cm}^{-1}$ attributed to the free-OH stretching alcohol/phenols, the sharp band at $2924 \mathrm{~cm}^{-1}$ arose from the stretching modes of alkanes $(\mathrm{C}-\mathrm{H})$, whereas the band at 2853 $\mathrm{cm}^{-1}$ corresponded to the aldehyde group (CHO). The medium 3 peaks at 2428, 2360 and $2341 \mathrm{~cm}^{-1}$ belonged to stretching phosphine $(\mathrm{P}-\mathrm{H})$, stretching silane (Si-H) and stretching phosphine $(\mathrm{P}-\mathrm{H})$ respectively. The remaining bands at 1617, 1384, 1268, 1044, 779, 666 and $617 \mathrm{~cm}^{-1}$ showed the presence of bending amines $(\mathrm{N}-\mathrm{H})$, stretching sulphate esters $(\mathrm{S}=\mathrm{O})$, wagging alkyl halides $\left(\mathrm{CH}_{2} \mathrm{X}\right)$, stretching amines $(\mathrm{C}-\mathrm{N})$, stretching meta di-substituted aromatics $(\mathrm{C}-\mathrm{H})$, stretching alkyl halides $(\mathrm{C}-\mathrm{Br})$ and bending alkynes $(\mathrm{C}-\mathrm{H})$, respectively, which were involved in the formation as well as in the reduction, capping and stabilization of AgNPs of $P$. roxburghii seed aqueous extract. The presence of the possible bio-reducing agents in the plant extract
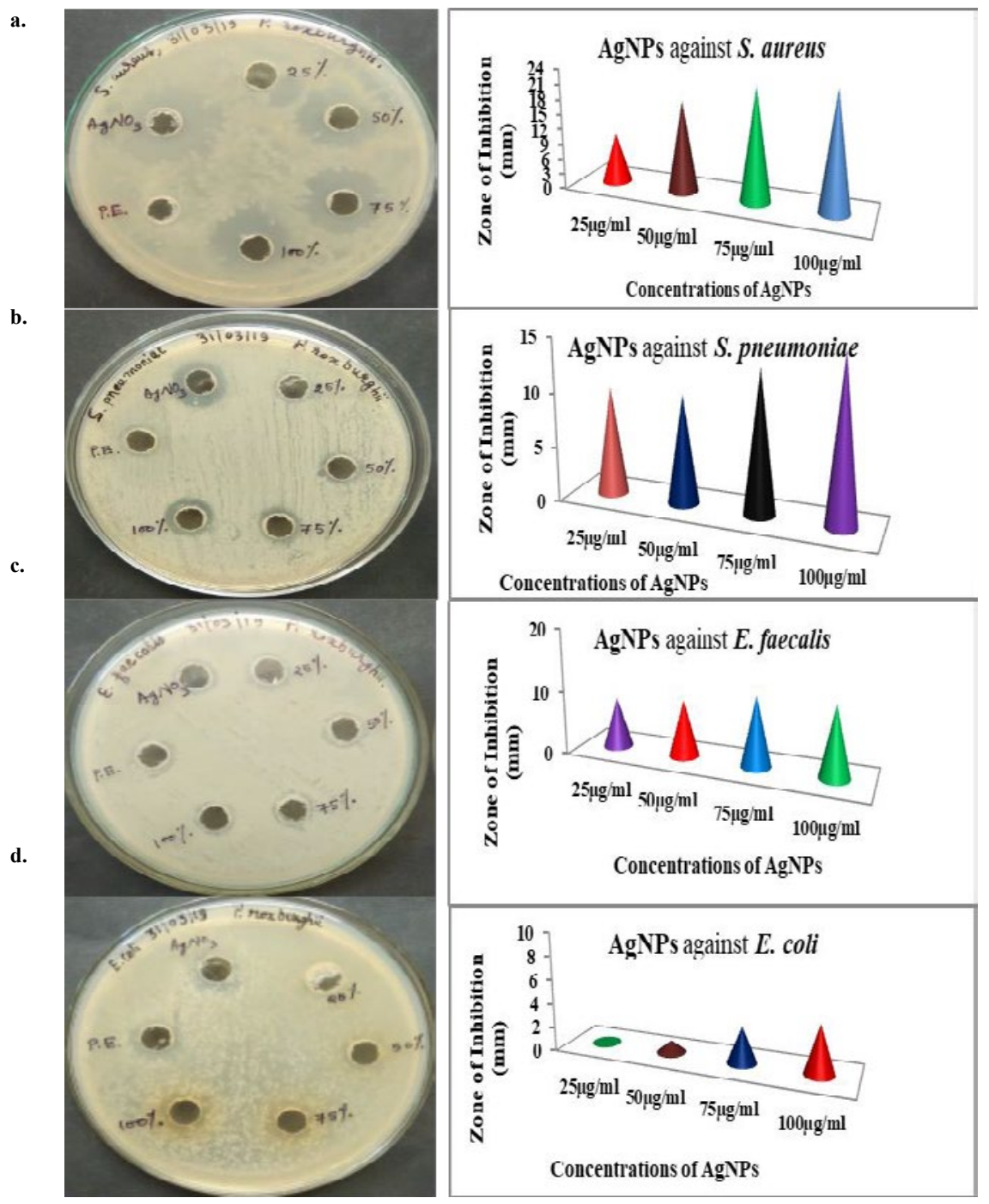

Fig. 9: Antibacterial effects and zones of inhibition produced by synthesized AgNPs Effects of AgNPs on a) $S$. aureus b) $S$. pneumoniae c) $E$. faecalis and d) $E$. coli 
used and the synthesized AgNPs were confirmed by the FTIR analysis ${ }^{[19,26]}$.

Antibacterial activity of AgNPs was studied at 25, 50, 75 and $100 \mu \mathrm{g} / \mathrm{ml}$ concentrations and the concentrations above $100 \mu \mathrm{g} / \mathrm{ml}$ were not studied. The $\mathrm{AgNO}_{3}$ solution was taken as positive control and the plant extract as a negative control. The formation of zones of inhibition at different concentrations of AgNPs is shown in fig. 8. The zones of inhibition was more for $100 \mu \mathrm{g} / \mathrm{ml}$ concentration against all organisms tested and that E. coli was less-sensitive compared to the three organisms to AgNPs prepared from $P$. roxburghii seed extract. $S$. aureus was more sensitive than the other bacteria tested and 10, 18, 22 and $23 \mathrm{~mm}$ of inhibition zones were obtained with $25,50,75$ and $100 \mu \mathrm{g} / \mathrm{ml}$ concentrations of AgNPs, respectively. The results of the antibacterial activity were shown in fig. 9. Some other authors also stated that gram-positive bacteria were more sensitive to AgNPs compared to gram-negative bacteria ${ }^{[29,30]}$. Depending upon the concentration of AgNPs exposed to bacteria and the type of bacteria, different inhibition zones are formed and along with that the structural and molecular compositions of bacterial species ${ }^{[31]}$ and inoculated concentration of bacteria and the size, shape, concentrations of AgNPs contribute to the varying results of inhibition zones ${ }^{[32]}$.

The human breast cancer cell line (MCF-7) was selected due to the high incidence of breast cancer in India ${ }^{[33]}$ to study the cytotoxic activity of the synthesized AgNPs using MTT assay. When treated with concentrations of AgNPs between 12.5 to $200 \mu \mathrm{g} / \mathrm{ml}$, about $50 \%$ of MCF-7 cells died. The cell cytotoxicity results from

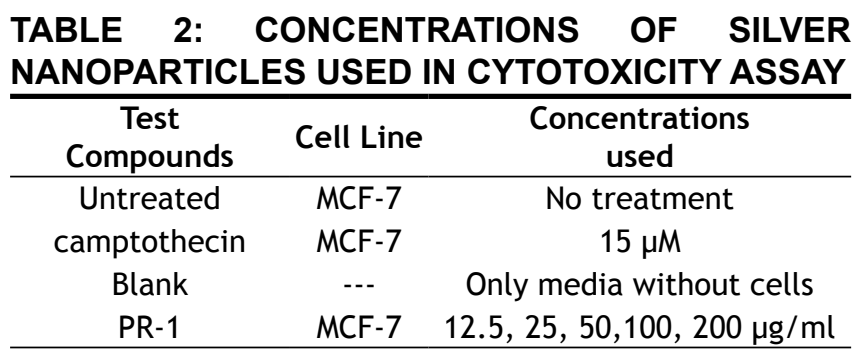

PR-1 stands for Putranjiva roxburghii, MCF-7 stands for Michigan Cancer Foundation-7 a
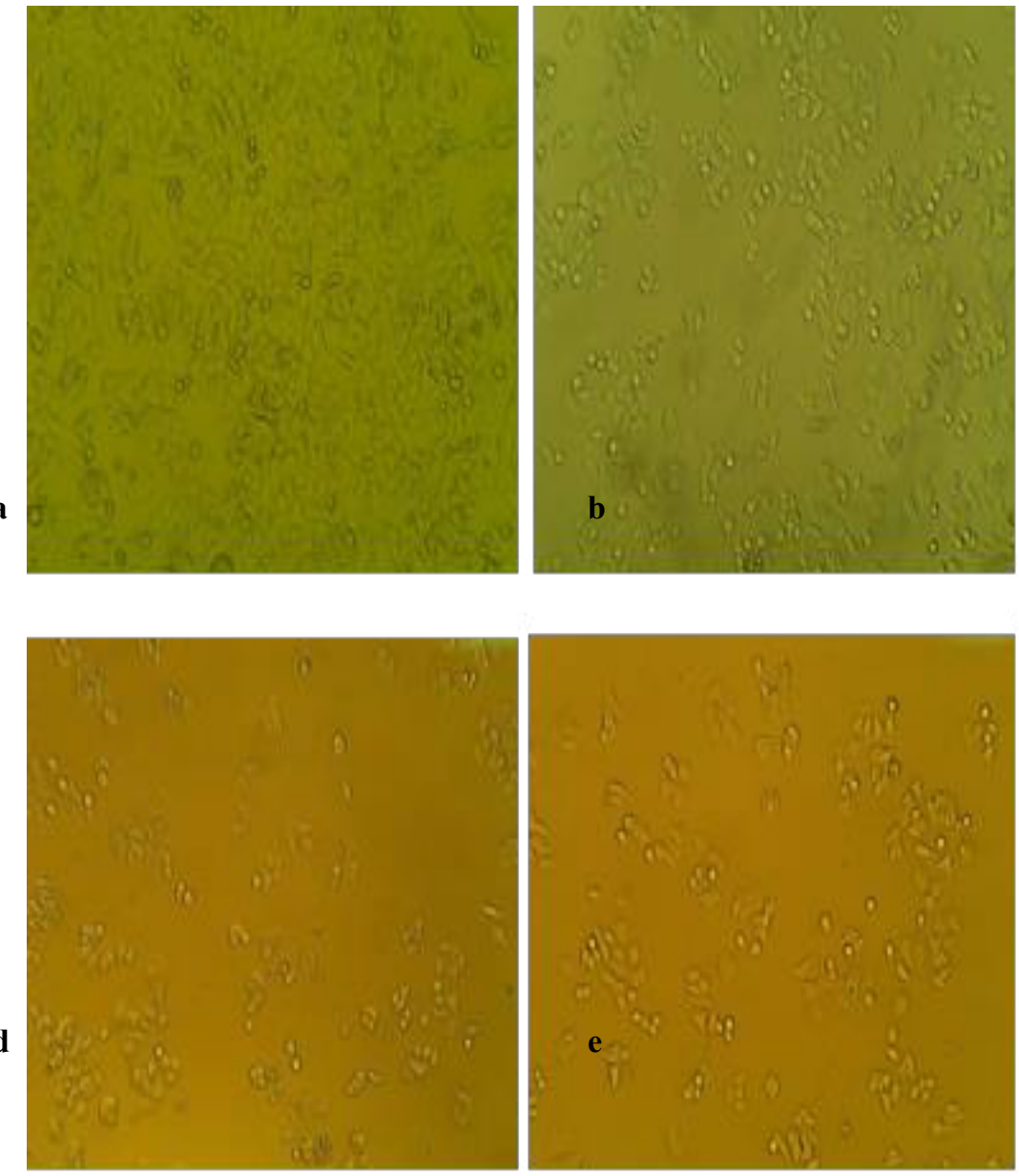

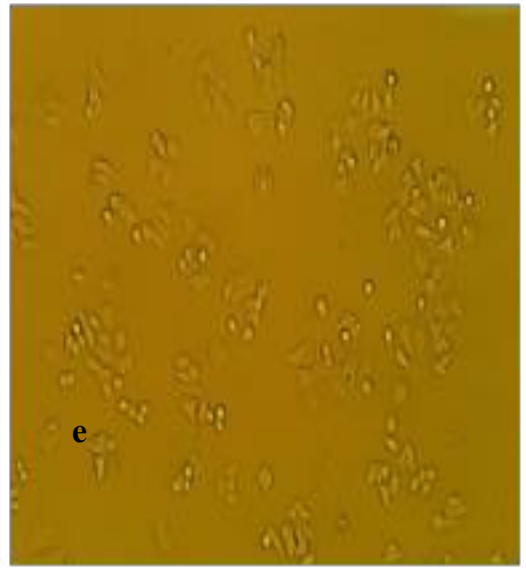

Fig. 10: Cytotoxicity of synthesized AgNPs against MCF-7 cell line a) MCF-7 control cells b) cells treated with $12.5 \mu \mathrm{g} / \mathrm{ml}$ c) cells treated with $25 \mu \mathrm{g} / \mathrm{ml} \mathrm{d}$ ) cells treated with $50 \mu \mathrm{g} / \mathrm{ml}$ e) cells treated with $100 \mu \mathrm{g} / \mathrm{ml}$ and f) cells treated with $200 \mu \mathrm{g} / \mathrm{ml} \mathrm{of} \mathrm{AgNPs}$ 


\section{PR 1 vs MCF7}

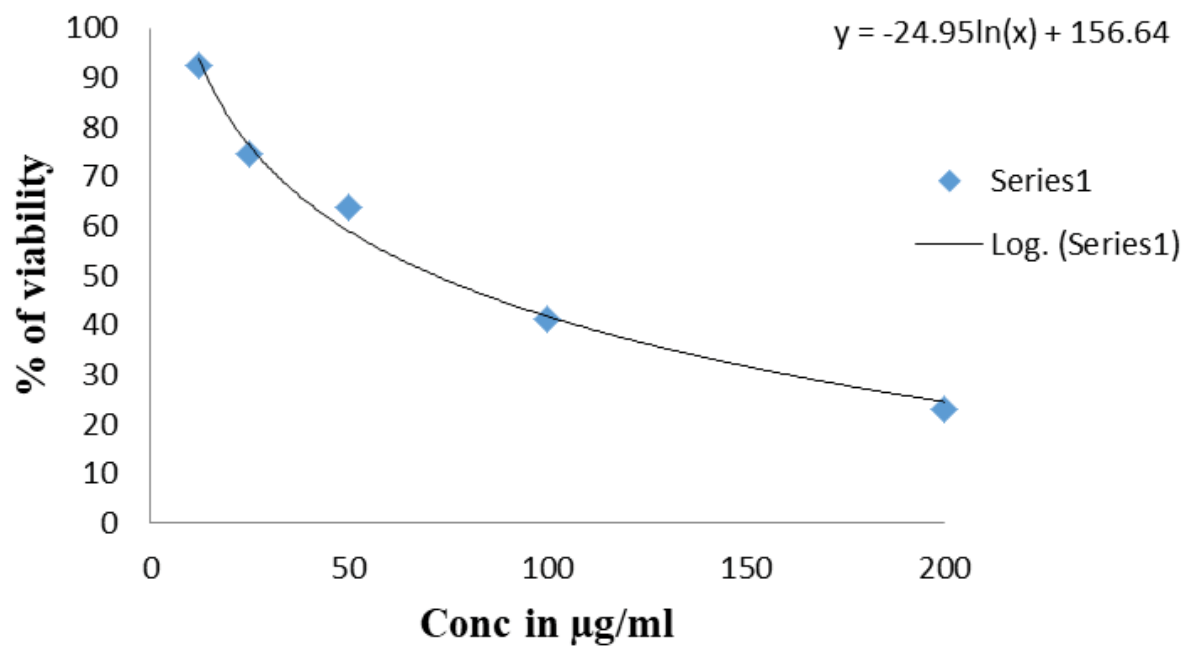

Fig. 11: Reduction in \% viability of MCF-7 cells with increasing concentrations of AgNPs

the ELISA reader showed that against MCF-7 cells, P. roxburghii seed extract NPs showed $\mathrm{IC}_{50}$ at $72.32 \mu \mathrm{g} /$ $\mathrm{ml}$. The morphological changes of breast carcinoma cell line MCF-7 at different concentration of samples along with the untreated cells were recorded using an inverted phase-contrast tissue culture microscope. The rounding or shrinking of the cells or other morphological changes in the cells to varying degree was visible in the images and it was a clear indication of the cytotoxic effect of synthesized AgNPs. MCF-7 cells treated with different concentrations of AgNPs were shown in fig. 10 and Table 2, respectively and the reduction in \% viability of MCF-7 cells with increasing AgNPs concentrations was shown in fig. 11. The synthesized AgNPs exhibited dose-dependent cytotoxic effects on breast cancer cells in vitro $^{[34]}$. AgNPs synthesised from Embelia ribes showed potential anticancer activity against MCF7cells ${ }^{[35]}$, Bauhinia tomentosa against A-549, Hep-2 and MCF-7 cells ${ }^{[36]}$. AgNPs synthesized from plant extracts exhibited remarkable antitumour activity against MCF7, HT29 and EAC cell lines ${ }^{[37]}$, the AgNPs from Salacia chinensis showed anticancer activity with $\mathrm{IC}_{50}$ values ranging from 4.0 to $14.37 \mu \mathrm{g} / \mathrm{ml}$ against seven selected cancer cell lines ${ }^{[38]}$, also another report suggested that the AgNPs from plant extracts exhibited considerable cytotoxic activity against almost all tested human cancer cell lines ${ }^{[39]}$.

The results of the present study showed that the $P$. roxburghii seed extract is a good reducing agent to prepare AgNPs via green synthesis, ranging 10 to $70 \mathrm{~nm}$ in size (average $25.68 \mathrm{~nm}$ ). It was found to be an ideal method for eco-friendly synthesis of inexpensive AgNPs. The antibacterial activity of the
AgNPs was tested on both gram-positive and gramnegative bacteria and the AgNPs showed activity at concentrations ranging from $25-100 \mu \mathrm{g} / \mu \mathrm{l}$. Further, the cytotoxic activity of these AgNPs was tested on MCF-7 cell line to find that $>12.5 \mu \mathrm{g} / \mathrm{ml}$ of AgNPs reduced cell proliferation and \% cell viability giving rise to a possibility that these NPs could be developed as potential anticancer agents.

\section{Acknowledgements}

The authors are grateful to the chairman of the Department of Studies in Botany, Karnatak University, Dharwad for extending laboratory facilities. The authors wish to thank the University Scientific Instrument Centre (USIC), Karnatak University Dharwad for providing instrumentations facilities.

\section{Conflicts of Interest:}

The authors declare that there is no conflict of interests.

\section{REFERENCES}

1. Sivaranjani T, Asha A, Thirunavukkarasu P, Asha S. Silver nanoparticle synthesis from plant extracts and its applications - A review. Int J Adv Res Phys Sci 2016;3(3):5-8.

2. Mansour GM, Robabeh HD, Mostafa, Mansoureh R, Kamyar $\mathrm{S}$. Green synthesis of silver nanoparticles using plant extracts. Korean J Chem Eng 2014;31(4):548-57.

3. Asim KS. Review on green synthesis of silver nanoparticles by physical, chemical and biological methods. Int J Sci Eng Res 2016;7(10):551-4.

4. Okafor F, Afef J, Kukhtareva T, Curley VEM. Green synthesis of silver nanoparticles their characterization, application and antibacterial activity. Int $\mathrm{J}$ Environ Res Public Health 2013;10:5221-38.

5. Chung IM, Park I, Seung-Hyun K, Rajakumar MTG. Plantmediated synthesis of silver nanoparticles: their characteristic 
properties and therapeutic applications. Nanoscale Res Lett 2016;11:40.

6. Iravani S. Green synthesis of metal nanoparticles using plants. Green Chem 2011;13:2638-50.

7. Akhtar MS, Jitendra P, Yeoung-Sang Y. Biogenic synthesis of metallic nanoparticles by plant extracts. ACS Sustain Chem Eng 2013;1:591-602.

8. Natsuki J, Natsuki T, Hashimoto Y. A review of silver nanoparticles: synthesis methods, properties and applications. Int J Mater Sci Appl 2015;4(5):325-32.

9. Quang HT, Anh-Tuan VQNL. Silver nanoparticles: synthesis, properties, toxicology, applications and perspectives. Adv Nat Sci Nanosci Nanotechnol 2013;4:1-20.

10. Sista KS, Giri DD, Pal DB, Mishra PK, Upadhyay SN. Green synthesis of silver nanoparticles: A review. Green Sustain Chem 2016;6:34-56.

11. Protima R, Küünal S, Ferdov S, Erwan R. A review on the green synthesis of silver nanoparticles and their morphologies studied via TEM. Adv Mater Sci Eng 2015:682749.

12. Ahmad N, Sharma S. Green synthesis of silver nanoparticles using extracts of Ananas comosus. Green Sustain Chem 2012;2:141-7.

13. Mukesh T, Ashok KJ. Biosynthesis of silver nanoparticles using plant extracts; new approach in agriculture \& pharmaceuticals: A review. Int J Innov Res Multidiscip Field 2017;3(6):1-7.

14. Umoren SA, Obot IB, Gasem ZM. Green synthesis and characterization of silver nanoparticles using red apple (Malus domestica) fruit extract at room temperature. J Mater Environ Sci 2014;5(3):907-14.

15. Unnikrishnan V, Nishteswar K. P. roxburghii- a herb for pumsavana (male progeny facilitator)?. Int J Ayurveda Pharm Res 2015;3(6):11-6.

16. Mradu G. A review of pharmacological properties, pharmacognosy and therapeutic actions of Putranjiva roxburghii Wall (P. roxburghii). Int J Herb Med 2016;4(6):1048.

17. Supriya B, Keerthana V, Nambirajan S, Dharmendira KM. Medicinal values of Putranjiva roxburghii-A review. Int J Cur Pharm Re 2017;9(5):5-8

18. Wantana R, Tassanee N, Sanan S. Antinociceptive, antipyretic, and anti-inflammatory activities of Putranjiva roxburghii Wall. leaf extract in experimental animals. J Nat Med 2009;63:2906.

19. Syed GA, Khan MH, Jalal M, Ansari MA, Abbas AM, Ahmad MK. Green synthesis of silver nanoparticles using the leaf extract of Putranjiva roxburghii wall. and their antimicrobial activity. Asian J Pharm Clin Res 2015;8(3):335-8.

20. Emasushan M, Britto JS. Preliminary phytochemical profiling and antifungal activity of the seeds and pericarp of Putranjiva roxburghii Wall. Pharm Innov 2018;7(4):107-10.

21. Sarath P, Sudha BR. A comparative evaluation of phytochemicals in bark, leaves and seeds of a. Putranjiva roxburghii Wall. (Putranjivaceae). J Pharm Phytochem 2019;8(1):1162-6.

22. Majeed S, Abdullah MS, Anima N. In vitro study of antibacterial and anticancer activity of silver nanoparticles synthesized from Penicillium Brevicompactum. J Taibah Univ Sci 2016;10:614-20.

23. Mosmann T. Rapid colourimetric assay for cellular growth and survival: application to proliferation and cytotoxicity assays. J Immunol Methods 1983;65(1-2):55-63.
24. Devanesan S, AlSalhi SM, Radhakrishnan VB, Ranjitsingh AAJ, Ahamed A, Alfuraydi AA, et al. Antimicrobial and cytotoxicity effects of synthesized silver nanoparticles from Punica granatum peel extract. Nanoscale Res Lett 2018;13: 315.

25. Zhang Xi-Feng, Zhi-Guo L, Wei S, Gurunathan S. Silver nanoparticles: synthesis, characterization, properties, applications, and therapeutic approaches. Int $\mathrm{J}$ Mol Sci 2016;17:1534

26. Anil K, Chetan B. Synthesis and characterization of silver nanoparticles using Luffa Cylindrica plant extract and study of their antimicrobial properties. Int J Adv Sci Eng Technol 2016;4(2-3):182-4.

27. Premasudha P, Venkataramana M, Marriappan A, Periyasamy V, Krishna K, Ramasamy R. Biological synthesis and characterization of silver nanoparticles using Eclipta alba leaf extract and evaluation of its cytotoxic and antimicrobial potential. Bull Mater Sci 2015;38(4):965-73.

28. Supakit P, Jongkon S, Septama AW, Supayang PV. Green synthesis of silver a. nanoparticles using plants from Myrtaceae family and characterization of their antibacterial activity. Mater Lett 2017;209:201-6.

29. Kayalvizhi T, Ravikumar S, Venkatachalam P. Green synthesis of metallic silver nanoparticles using Curculigo orchioides rhizome extracts and evaluation of its antibacterial, larvicidal, and anticancer activity. J Environ Eng 2016;142(9):1-10.

30. Paul B, Bishal B, Debraj DP, Siddhartha SD. Photocatalytic and antibacterial activity of gold and silver nanoparticles synthesized using biomass of Parkia roxburghii leaf. J Photochem Photobio B 2015;154:1-7.

31. Maheshkumar PP, Gun-Do K. Eco-friendly approach for nanoparticles synthesis and mechanism behind antibacterial activity of silver and anticancer activity of gold nanoparticles. Appl Microbiol Biotechnol 2017;101:79-92.

32. Rai MK, Deshmukh SD, Ingle AP, Gade AK. Silver nanoparticles: the powerful nanoweapon against multidrugresistant bacteria. J Appl Microbiol 2012;112:841-52.

33. Dandona L. The burden of cancers and their variations across the states of India: the Global Burden of Disease Study 1990-2016. Lancet Oncol 2018;19:1289-306.

34. Naz M, Nasiri N, Ikram M, Nafees M, Qureshi MZ, Ali S, et al. A Eco-friendly biosynthesis, anti-cancer drug loading and cytotoxic effect of capped Ag-nanoparticles against breast cancer. Appl Nanosci 2017;7:793-802.

35. Manikandan M, Prakash GD, Arun J, Nagendra NG, Mani U, Kathirvan K. Antibacterial and anticancer activities of silver nanoparticles biosynthesized using Embelia ribes Burm.f. berries extract. Indian. J Exp Biol 2019;57:175-180.

36. Mukundan D, Mohankumar R, Vasanthakumari R. Comparative study of synthesized silver and gold nanoparticles using leaves extract of Bauhinia tomentosa Linn. and their anticancer efficacy. Bull Mater Sci 2017;40(2):335-44.

37. Bodaiah B, Aswani YVVK, Vinay KV, Richardson PJ, Usha KM, Sudhakar P. Anticancer activity of plant mediated silver nanoparticles on selected cancer cell lines. J Chem Pharm Res 2016;8(8):376-81.

38. Kiran J, Sharada D, Dinesh D, Rajeshwari HR, Satveer J, Sunil $\mathrm{J}$, et al. Phytosynthesis of silver nanoparticles: characterization, biocompatibility studies and anticancer activity. ACS Biomater Sci Eng 2018;4:892-9.

39. Abdel-Fattah IW, Ali WG. On the anti-cancer activities of silver nanoparticles. J Appl Biotechnol Bioeng 2018;5(2):1-4. 